\title{
Effect of irradiation times on the polymerization depth of contemporary fissure sealants with different opacities
}

\section{Boniek Castillo Dutra Borges ${ }^{(a)}$ Gabriela Voany Galdino Bezerra(a) Janaína de Almeida Mesquita ${ }^{(a)}$ Márcia Rodrigues Pereira ${ }^{(b)}$ Flávio Henrique Baggio Aguiar(c) Alex José Souza dos Santos(a) Isauremi Vieira de Assunção Pinheiro(a)}

(a) Department of Dentistry, School of Dentistry, Federal University of Rio Grande do Norte (UFRN), Natal, RN, Brazil.

(b) Department of Chemistry, School of Chemistry, Federal University of Rio Grande do Norte (UFRN), Natal, RN, Brazil.

(c)Department of Restorative Dentistry, Piracicaba Dental School, State University of Campinas (UNICAMP), Piracicaba, SP, Brazil.

\section{Corresponding Author \\ Boniek Castillo Dutra Borges \\ Rua Minas Novas, 390, cs. 18 \\ Natal - Rio Grande do Norte - Brazil \\ CEP: 59088-725 \\ E-mail: boniek.castillo@gmail.com}

Received for publication on Dec 17, 2010 Accepted for publication on Feb 08, 2011

\begin{abstract}
The aim of this study was to evaluate the depth of curing of 10 contemporary blue light-activated dental flowable materials at several opacities, influenced by different irradiation times using FT-IR spectroscopy. Fifty-five specimens $(\mathrm{n}=5)$ with a 5 -mm diameter and 1 -mm thickness of translucent (Opallis Flow T), yellowed (Master Flow A2; Opallis Flow A2; Natural Flow A2; Fluroshield Yellowed), and opaque materials (Master Flow OA2; Natural Flow O; Opallis Flow OA3.5; Opallis Flow OP; Fluroshield White) were obtained at six curing times $(10 \mathrm{~s}, 20 \mathrm{~s}, 30 \mathrm{~s}$, 40s, 50s, and 60s) using a high-intensity LED (Coltolux, Coltène/Whaledent). The degree of conversion (DC) (\%) was obtained using the Nexus 470 FTIR Spectrometer (Nicolet Instruments, USA). The FTIR-ATR spectra for uncured and cured samples were analyzed using a $\mathrm{ZnSe}$ crystal. The top and bottom surfaces of the cured specimens were analyzed to obtain the depth of curing. Two-way ANOVA was used to analyze the data. The highest curing depth was obtained by Natural Flow OA2, while the lowest was shown by Master Flow OA2. The shortest curing time generated similar depths of cure in comparison with the most extensive for Opallis Flow A2 and Fluroshield Yellowed. Therefore, depth of curing, influenced by the irradiation time, was dependent on the materials. Using the Natural Flow OA2 opaque sealant and the 10-s curing time for Opallis Flow A2 and Fluroshield Yellowed may represent alternative approaches to sealing tooth fissures.
\end{abstract}

Descriptors: Pit and Fissure Sealants; Composite Resins; Pediatric Dentistry.

\section{Introduction}

Photoactivated dental composite resins are now the most widely used restorative material. The main advantage of this activation mode over the chemical one is the working time control by the operator. ${ }^{1,2}$ Lowviscosity light-cured materials such as traditional fissure sealants or flowable composites are routinely used in minimal intervention procedures, preventing caries initiation and arresting caries progression by providing a physical barrier that inhibits microorganisms and food particles from collecting in pits and fissures after polymerization. ${ }^{3}$

The polymerization process of a composite resin occurs through the conversion of the monomer molecules of the matrix into a polymer chain. ${ }^{4}$ The extent to which the monomer is converted into a polymer is 
denominated degree of conversion (DC). The polymerization of the monomer BisGMA occurs through the carbon-carbon double bond of the two methacrylate groups. ${ }^{5}$ Depth of curing is a crucial factor in obtaining the optimal physical properties and clinical performance of dental composite resins. ${ }^{6}$ Low DC values on the top and bottom surfaces of the material placed on tooth fissures are associated with bacterial growth ${ }^{7}$ and sealant debonding, ${ }^{8}$ respectively, leading to clinical failure. Therefore, the optimal depth of curing for these materials is crucial in obtaining satisfactory clinical performance.

Factors such as exposure time, monomer composition, and opacity of the material have significant effects on the depth of curing of composite resins., ${ }^{2,3,9}$ The materials' DC is proportional to the amount of light to which they are exposed. ${ }^{2}$ Concerning material opacity, translucent, yellowed, or opaque fissure sealants are commercially available. The more opaque it is, the lower the light absorption and transmittance to the bottom surface of the material will be, ${ }^{8}$ so short curing times may provide insufficient depth of curing. Since materials of all opacities are usually utilized in children, the investigation of the shortest curing time that is sufficient to provide the highest depth of curing could facilitate their application without generating undesirable weak physical properties after polymerization. However, the literature is scarce in research studies evaluating the effect of different curing times on the depth of curing of several fissure sealants with various opacities. Therefore, this study aimed to evaluate the depth of curing of 10 translucent, yellowed, and opaque contemporary fissure sealants as influenced by various polymerization times. The null hypothesis tested was that there would be no differences among the materials and curing times.

\section{Materials and Methods Experimental design}

The factors under study were:

- materials at 10 levels:

- Opallis Flow T (FGM, Joinville, Brazil),

- Opallis Flow A2 (FGM, Joinville, Brazil),

- Master Flow A2 (Biodinâmica, Ibiporã, Brazil),

- Natural Flow A2 (DFL, Rio de Janeiro, Brazil),

- Fluroshield Yellowed (Dentsply/Caulk, Rio de
Janeiro, Brazil),

- Master Flow OA2 (Biodinâmica, Ibiporã, Brazil),

- Natural Flow O (DFL, Rio de Janeiro, Brazil),

- Opallis Flow OA3.5 (FGM, Joinville, Brazil),

- Opallis Flow OP (FGM, Joinville, Brazil),

- Fluroshield White (Dentsply/Caulk, Rio de Janeiro, Brazil);

- and curing time at six levels:

- 10s,

$-20 \mathrm{~s}$,

$-30 s$,

- 40s,

$-50 s$, and

$-60 s$.

Depth of curing by means of degree of conversion (DC) analysis for the top and bottom surfaces of the samples was performed.

The materials' composition, opacities, and batch numbers are shown in Table 1 . The physical characteristics of the light-curing unit used in the study are listed in Table 2.

\section{Sample preparation}

Cylinder Teflon molds $(5 \mathrm{~mm}$ diameter x $1 \mathrm{~mm}$ height) (Ferramentas ALFA, São Paulo, Brazil) were used to fabricate 330 specimens ( $\mathrm{n}=5$ per group). The low-viscosity materials were injected into the center of the matrix using the disposable tip supplied by the manufacturer under controlled temperature and relative humidity conditions. The material surfaces were covered with a Mylar strip (K-Dent - Quimidrol, Joinville, Brazil) and then photoactivated using the light-emitting diode (LED) Coltolux (Coltène/Whaledent, Altstätten, Switzerland) at a 3-mm distance. ${ }^{3}$ After polymerization, the specimens were removed from the matrices and stored dry in light-proof containers at $37^{\circ} \mathrm{C}$ for 24 hours. ${ }^{8}$

\section{DC analysis}

The number of double-carbon bonds converted into single bonds provides the DC of the composite resin. The measurements for the DC (\%) were made with a Nexus 470 FTIR Spectrometer (Nicolet Instruments Inc., Madison, USA), using an ATR (attenuated total reflectance) accessory, 32 scans, 
Table 1 - Composition and batch number of the dental flowable materials used in this study.

\begin{tabular}{|c|c|c|c|}
\hline $\begin{array}{l}\text { Commercial name } \\
\text { (manufacturer) }\end{array}$ & Opacity & Batch & Composition by weight \\
\hline $\begin{array}{l}\text { Opallis Flow T (FGM, } \\
\text { Joinville, Brazil) }\end{array}$ & Translucent & 151009 & $\begin{array}{l}\text { UDMA }^{A}(5-10 \%) \text {, TEGDMA } \\
\text { inorganic }(5-10 \%) \text {, } \mathrm{Al} \text {-Si micro-particles, and } \mathrm{SiO}_{2} \text { in }(5-10 \%) \text {, silanized } \\
5.0 \mu \mathrm{m})(72 \%)\end{array}$ \\
\hline $\begin{array}{l}\text { Opallis Flow A2 (FGM, } \\
\text { Joinville, Brazil) }\end{array}$ & $\begin{array}{l}\text { Yellowed } \\
\text { (A2 shade) }\end{array}$ & 140610 & $\begin{array}{l}U_{D M A}^{A}(5-10 \%), T^{T E G D M A}(5-10 \%), \mathrm{Bis}^{\mathrm{B}} \mathrm{EMA}^{\mathrm{C}}(5-10 \%) \text {, silanized } \\
\text { inorganic filler Ba-Al-Si micro-particles, and } \mathrm{SiO}_{2} \text { in nanoparticles }(0.05 \\
\text { and } 5.0 \mu \mathrm{m})(72 \%)\end{array}$ \\
\hline $\begin{array}{l}\text { Master Flow A2 } \\
\text { (Biodinâmica, Ibiporã, } \\
\text { Brazil) }\end{array}$ & $\begin{array}{l}\text { Yellowed } \\
\text { (A2 shade) }\end{array}$ & 06810 & $\begin{array}{l}\left.\text { Bis-GMA }{ }^{D}(34.33 \%), U D M A^{A}(\%)^{*} \text {, inorganic filler (35.7\%) (filler size: } n f\right) \text {, } \\
\text { pigments, and catalysts }\end{array}$ \\
\hline $\begin{array}{l}\text { Natural Flow A2 (DFL, Rio } \\
\text { de Janeiro, Brazil) }\end{array}$ & $\begin{array}{l}\text { Yellowed } \\
\text { (A2 shade) }\end{array}$ & 10060693 & $\begin{array}{l}\text { Bis-GMAD }(\%)^{*} \text {, dimethacrylate resins }(\%)^{*}, \text { Ba-Al-Si glass, and synthetic } \\
\text { silica filler (43\%) (filler size: } n f \text { ) and dyes }\end{array}$ \\
\hline $\begin{array}{l}\text { Fluroshield Yellowed } \\
\text { (Dentsply/Caulk, Rio de } \\
\text { Janeiro, Brazil) }\end{array}$ & Yellowed & $248206 C$ & 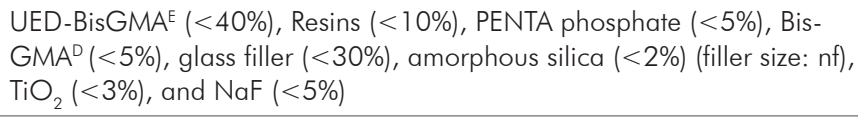 \\
\hline $\begin{array}{l}\text { Master Flow OA2 } \\
\text { (Biodinâmica, lbiporã, } \\
\text { Brazil) }\end{array}$ & $\begin{array}{l}\text { Opaque } \\
\text { (OA2 shade) }\end{array}$ & 06010 & $\begin{array}{l}\text { Bis-GMA }{ }^{D}(34.33 \%), U^{\prime} A^{A}(\%)^{*} \text {, inorganic filler }(35.7 \%), \text { pigments, } \\
\text { and catalysts }\end{array}$ \\
\hline $\begin{array}{l}\text { Natural Flow } O(D F L, \text { Rio } \\
\text { de Janeiro, Brazil) }\end{array}$ & Opaque (O shade) & 10020254 & $\begin{array}{l}\text { Bis-GMAD }(\%)^{*} \text {, dimethacrylate resins }(\%)^{*}, \text { Ba-Al-Si glass, and synthetic } \\
\text { silica filler (43\%) (filler size: nf) and dyes }\end{array}$ \\
\hline $\begin{array}{l}\text { Opallis Flow OA3.5 } \\
\text { (FGM, Joinville, Brazil) }\end{array}$ & $\begin{array}{l}\text { Opaque } \\
\text { (OA3.5 shade) }\end{array}$ & 150210 & $\begin{array}{l}U_{D M A}^{A}(5-10 \%) \text {, TEGDMA } A^{B}(5-10 \%) \text {, Bis-EMA } A^{C}(5-10 \%) \text {, silanized } \\
\text { inorganic filler Ba-Al-Si micro-particles, and } \mathrm{SiO}_{2} \text { in nanoparticles }(0.05 \\
\text { and } 5.0 \mu \mathrm{m})(72 \%)\end{array}$ \\
\hline $\begin{array}{l}\text { Opallis Flow OP (FGM, } \\
\text { Joinville, Brazil) }\end{array}$ & $\begin{array}{c}\text { Extra opaque } \\
\text { (OP shade) }\end{array}$ & 290410 & $\begin{array}{l}\text { UDMA }^{A}(5-10 \%) \text {, TEGDMA } A^{B}(5-10 \%) \text {, Bis-EMA }{ }^{C}(5-10 \%) \text {, silanized } \\
\text { inorganic filler Ba-Al-Si micro-particles, and } \mathrm{SiO}_{2} \text { in nanoparticles }(0.05 \\
\text { and } 5.0 \mu \mathrm{m})(72 \%)\end{array}$ \\
\hline $\begin{array}{l}\text { Fluroshield White } \\
\text { (Dentsply, Rio de Janeiro, } \\
\text { Brazil) }\end{array}$ & Opaque & 13307 & $\begin{array}{l}\text { UED-BisGMAE }(<40 \%) \text {, resins }(<10 \%) \text {; PENTA phosphate }(<5 \%) \text {, Bis- } \\
\left.\mathrm{GMA}^{\mathrm{D}}(<5 \%) \text {, glass filler }(<30 \%) \text {, amorphous silica }(<2 \%) \text { (filler size: } n f\right) \text {, } \\
\mathrm{TiO}_{2}(<3 \%) \text {, and } \mathrm{NaF}(<5 \%)\end{array}$ \\
\hline
\end{tabular}

AUrethane Dimethacrylate; BTriethylene Glycol Dimethacrylate; CEtoxilated Bisphenol A. Diglicidil Methacrylate; DBisphenol A-Glycidyl Methacrylate; EUrethane modified Bis-GMA dimethacrylate. *The manufacturer did not provide the percentage of UDMA; nf: not furnished by the manufacturer.

Table 2 - Physical characteristics of the curing-light unit used in the study.

\begin{tabular}{|c|c|c|c|c|c|}
\hline $\begin{array}{l}\text { Light-curing } \\
\text { unit }\end{array}$ & Manufacturer & $\mathrm{PD}^{\mathrm{A}}$ & $\mathrm{PD}^{\mathrm{B}}$ & $\begin{array}{l}\text { Wavelength } \\
\text { range }\end{array}$ & $\begin{array}{c}\text { Wavelength } \\
\text { peak }\end{array}$ \\
\hline $\begin{array}{c}\text { Coltolux } \\
\text { LED (serial } \\
\text { 091215032) }\end{array}$ & $\begin{array}{c}\text { Coltène/Whaledent, } \\
\text { Altstätten, } \\
\text { Switzerland }\end{array}$ & $\begin{array}{c}>1000 \mathrm{~mW} / \\
\mathrm{cm}^{2}\end{array}$ & $\begin{array}{c}900 \mathrm{~mW} / \\
\mathrm{cm}^{2}\end{array}$ & $450-470 \mathrm{~nm}$ & $460 \mathrm{~nm}$ \\
\hline
\end{tabular}

APower density published by the manufacturer; ${ }^{B}$ Power density at 3-mm distance. The radiance was measured with a curing radiometer (model 100; Demetron Research Corporation, Danbury, CT, USA). A 3-mm distance was established using a digital caliper coupled to a metallic support.
$4 \mathrm{~cm}^{-1}$ resolution, and from 300 to $4000 \mathrm{~cm}^{-1}$ wavenumber. The top and bottom surfaces of the cured specimens were analyzed to determine the depth of curing. The percentage of unreacted carbon-carbon double bonds $(\% \mathrm{C}=\mathrm{C})$ was determined from the ratio of the absorbance intensities of aliphatic $\mathrm{C}=\mathrm{C}$ (peak at $1638 \mathrm{~cm}^{-1}$ ) against an internal standard be- fore and after the curing of the specimen: aromatic $\mathrm{C}-\mathrm{C}$ (peak at $1608 \mathrm{~cm}^{-1}$ ). The degree of conversion was determined by subtracting the $\% \mathrm{C}=\mathrm{C}$ from $100 \%$, according to the following equation:

DC $(\%)=1-\frac{\left(1638 \mathrm{~cm}^{-1}-1608 \mathrm{~cm}^{-1}\right) \text { cured }}{\left(1638 \mathrm{~cm}^{-1}-1608 \mathrm{~cm}^{-1}\right) \text { uncured }} \times 100$ 


\section{Statistical analysis}

The data were first submitted to two-way analysis of variance (ANOVA). The top, bottom, and bottom-to-top conversion ratios were considered separately. Multiple comparisons among the groups were analyzed by means of Tukey's test. All statistical tests were executed using the ASSISTAT Software (Federal University of Campina Grande, Campina Grande, Brazil) at the level of 5\%.

\section{Results}

\section{Top surface DC (\%)}

Figure 1 shows DC means of the materials' top surfaces at each curing time. In all of them, the Natural Flow $\mathrm{O}$ composite presented the highest DC, while the lowest DC values were shown by the Mas- ter Flow OA2 composite. The shortest curing time evaluated in this study (10 s) provided similar DC means to those of Natural Flow O, Fluroshield Yellowed, and Fluroshield White. Only Master Flow OA2 had the highest DC means at 60 s. Opallis Flow T, Opallis Flow A2, Natural Flow A2, Master Flow A2, Opallis Flow OA3.5, and Opallis Flow OP, respectively, presented the highest DC at the following photoactivation times: 30 s, 40s, 40s, and 20s.

\section{Bottom surface DC (\%)}

Figure 2 shows DC means of the materials' bottom surface at each curing time. In all of them, the Natural Flow O composite presented the highest DC, while the lowest DC values were shown by the Master Flow OA2 composite, as also occurred on
Figure 1 - Degree of conversion means (\%) of the materials' top surface at different curing times.

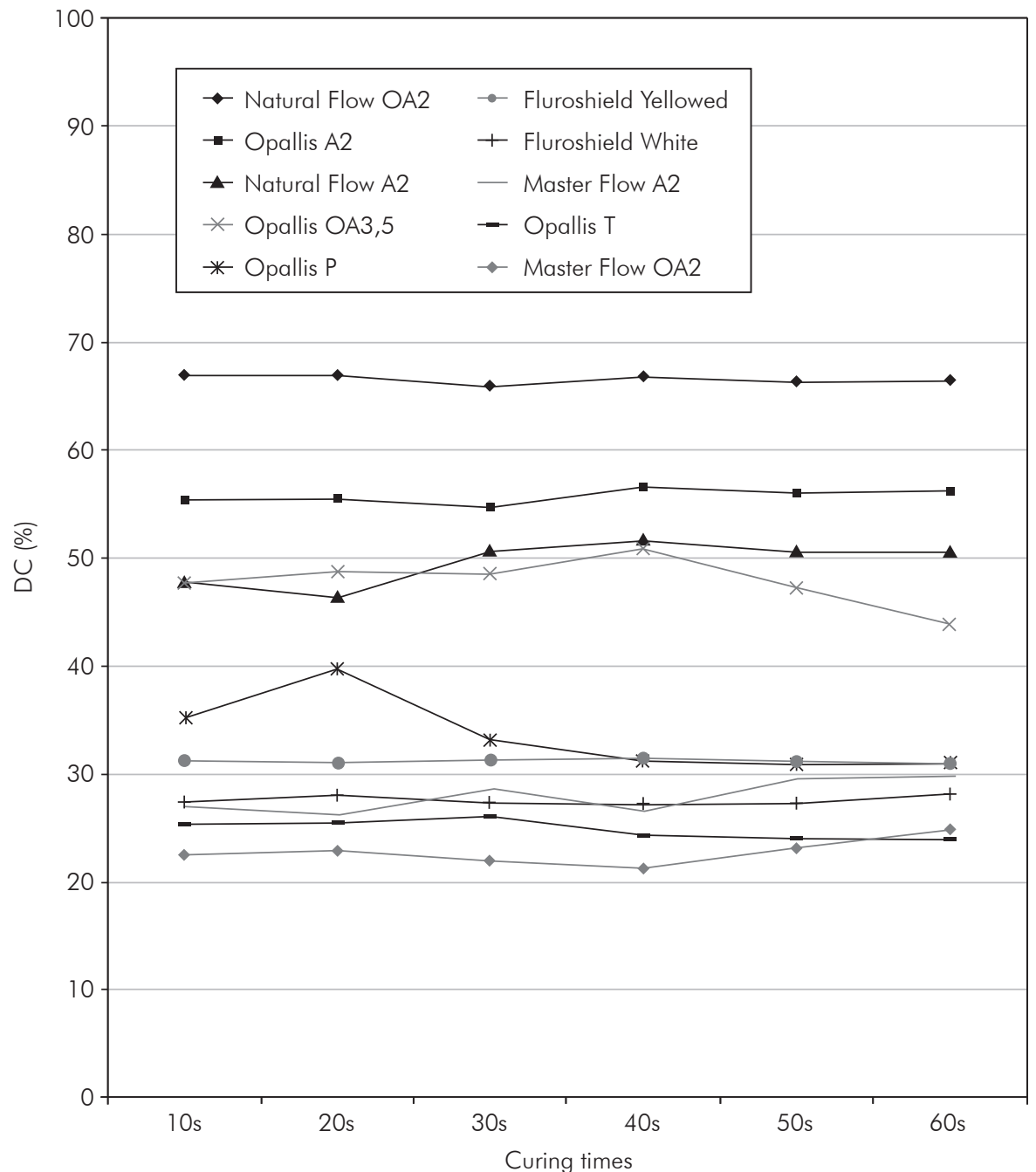


the top surface. The 10 -s curing time provided similar DC values to the 60-s results for Opallis Flow A2 and Fluroshield Yellowed. Also, only Master Flow OA2 had the highest DC means at 60s. Opallis Flow T, Natural Flow A2, Master Flow A2, Natural Flow O, Opallis Flow OA3.5, Opallis Flow OP, and Fluroshield White, respectively, presented the highest DC at the following photoactivation times: $10 \mathrm{~s}$, 30s, 30s, 20s, 40s, 20s, and 20s.

\section{Bottom-to-top DC ratio}

Most ratio values were higher than 0.8 , except for that of Opallis Flow OP at 10s (0.76) (Figure 3). For Opallis Flow A2, Natural Flow A2, Fluroshield Yellowed, and Natural Flow O, there were no differ- ences among curing times, so the 10-s curing time provided similar bottom-to-top DC ratio values to the others. The highest value was found for Opallis Flow OP when polymerized for 30s. However, the lowest bottom-to-top DC ratios were shown by Opallis Flow OP at 10-s, 40-s, and 60-s curing times.

\section{Discussion}

The clinical success of sealants is well-documented in the literature and directly related to its capacity to remain bonded to occlusal pits and fissures. ${ }^{10}$ The hardened material forms a strong micromechanical bond to etched tooth enamel, thus physically obturating susceptible areas of the tooth surface and preventing dental caries. Therefore, ensuring sufficient

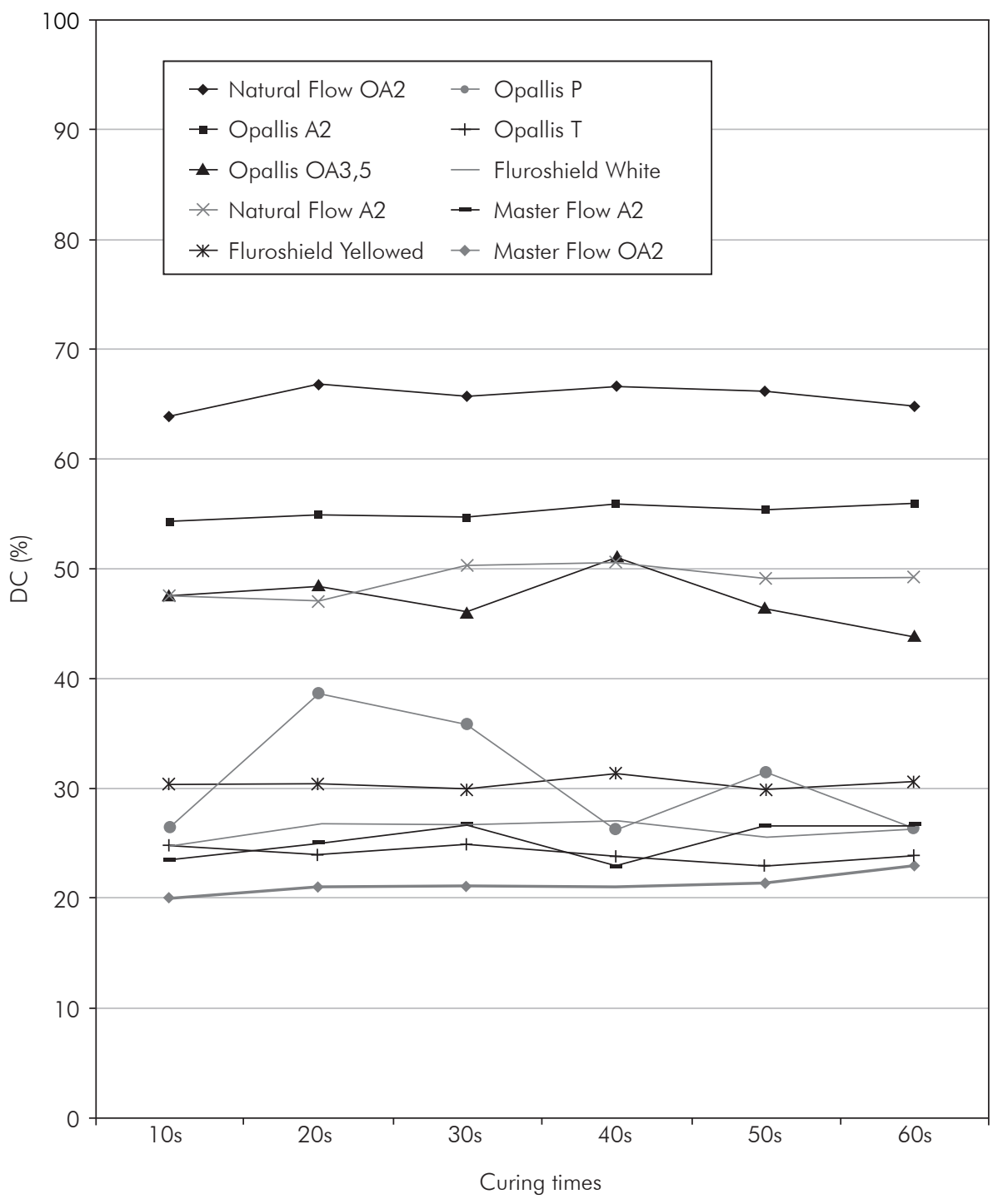

Figure 2 - Degree of conversion means (\%) of the materials' bottom surface at different curing times. 
Figure 3 - Bottom-to-top surface conversion ratio means (standard deviations) of the materials at different curing times.

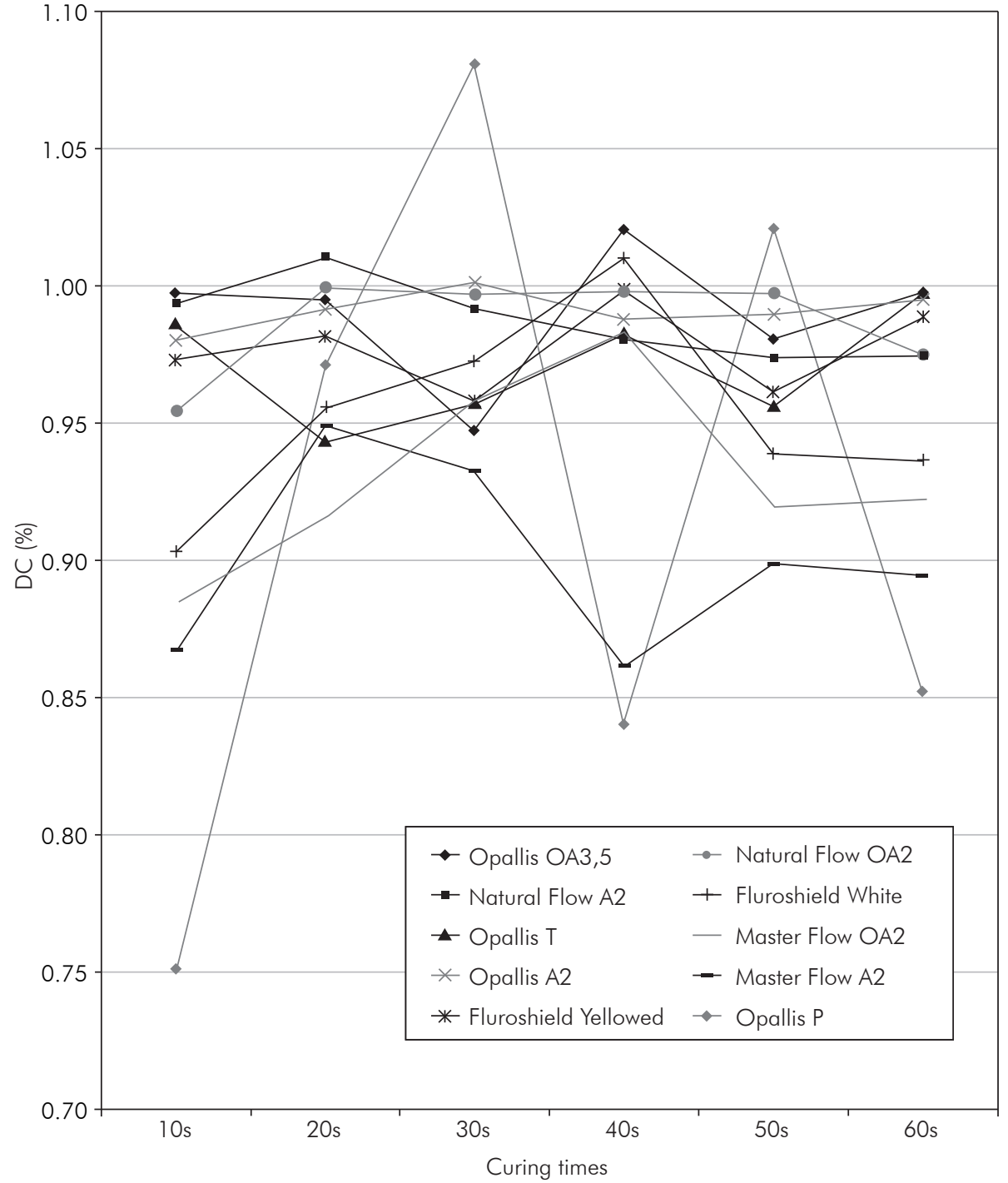

curing is an integral requirement for the success and longevity of a tooth fissure sealant. ${ }^{8}$

A direct relationship exists between the light intensity and DC of different composite resins. ${ }^{11}$ In this sense, it was found that an extended irradiation time (60s) to polymerize a dental flowable material (Permaflo, Ultradent, USA) increased the DC on its top surface, ${ }^{3}$ which could improve the clinical performance of tooth fissure sealer materials. Nevertheless, in the above-mentioned study, the bottom surfaces of the samples were not analyzed to assess the depth of curing. Moreover, considering that these materials are usually used in pediatric dentistry, there is a need to investigate a shorter curing time that is sufficient to provide similar physical properties to the 60 -s curing time for other flowable materials with several opacities. This would facilitate the application and decrease the drawbacks of a polymer with low DC.

The results obtained in this study showed that the major opaque sealants presented poorer conversion on either the top or bottom surface than the yellowed sealants. This finding corroborates other findings showing higher curing susceptibility for clearer/yellowed sealants in comparison with opaque sealants. ${ }^{8}$ The difference in curing characteristics between clear and opaque sealants most likely is related to the opacifying agents present in the opaque sealant, which probably cause substantial reflection, scattering, and absorption of light, 
preventing more curing through the surface of the sealant. ${ }^{8}$ As a result, the polymerization reaction is attenuated and the DC of these materials is lower than for non-opaque materials.

However, the better curing depth of Natural Flow $\mathrm{O}$ in comparison to its yellowed version (Natural Flow A2) was found in this work. Probably, the chemical components of this material caused a contrary effect regarding reflection, scattering, and absorption of light. Besides the irradiation time provided by visible light sources and the opacity characteristics of the dental materials, the refractive index difference that exists between the base resin and inorganic components (especially the silica) influences the transmission of visible light through the material. The higher the refractive index is, regardless of whether it increases during the polymerization phase of the monomers, the higher the light scattering and the lower the light transmission will be. ${ }^{12}$ Moreover, light transmission can decrease with time as the refractive index of the curing resin rises above that of the filler. ${ }^{13}$ Therefore, possibly, although Natural Flow $\mathrm{O}$ contains opacifying agents, the resultant refraction index before and after curing may favor higher monomer conversion, unlike Natural Flow A2 and other opaque materials. Although further studies are needed to confirm this supposition, the advantage of using an opaque material is the possibility of masking dark coloration on the bottom of the tooth fissures, increasing patient satisfaction.

In a clinical environment, the materials used to seal tooth fissures usually present a 1-mm thickness. ${ }^{3}$ Depending on the cusp size and the morphology of pits and fissures, the light guide of the curing unit may be placed at different distances from the sealant surface during occlusal sealing, such as $3 \mathrm{~mm}$, increasing the dispersion and decreasing the irradiance of the light that reaches the material. ${ }^{3}$ Therefore, both distance and sample thickness had to be considered during the sample preparation to approximate clinical conditions. Since a high-intensity LED was used, the radiance decrease after positioning the light tip at $3 \mathrm{~mm}$ from the material probably did not affect the DC. The fact that, for some brands (Opallis Flow A2 and Fluroshield Yellowed), even the 10-s irradiation time could provide a DC similar to that provided by the 60-s curing time on the bottom surface might be attributed to the aforementioned points. Also, a probable refraction index of the resin matrix that was close to the inorganic components, which may have not changed during polymerization, would explain this finding for both these materials.

Light-cured dental materials contain a lightsensitive initiator agent, usually an alpha-diketone. Among the diketones available, the most frequently used is camphorquinone (CQ). ${ }^{14}$ This photosensitizer absorbs light at wavenumbers between 460 and $480 \mathrm{~nm}$, reaching a triplete excited state. CQ is the photosensitizing agent used in most of the brands available on the market. Camphorquinone is an intensely yellow-colored powder. Additionally, it has poor photobleaching, which means that the yellow color remains the same after light irradiation. Thus, CQ addition turns the material yellowish, making it difficult to incorporate when lighter shades are desired, ${ }^{15}$ so lower amounts of CQ are usually present in translucent composites. In this case, alternative photoinitiators such as monoacylphosphine oxide (MAPO), bisacylphosphine oxide (BAPO), or phenylpropanedione (PPD) may also be present in composites of light shades to decrease the yellowing generated by CQ. ${ }^{16}$ However, these chemical agents exhibit the maximum light absorption centered in the ultra-violet A (UV-A) region. This may explain the finding that Opallis Flow $\mathrm{T}$ (translucent shade) presented lower conversion than other formulations made by the same manufacturer (FGM, Joinville, SC, Brazil). It is likely that the peak wavelength at 460 emitted by the light source used in this study did not excite all the photoinitiator molecules of this material, decreasing the DC.

The high bottom-to-top DC ratio obtained in this study indicated that the bottom and top surfaces had similar DC, and not because these surfaces had sufficiently high DC. This supposition may be explained because Opallis Flow OP presented the highest and the lowest DC ratios, even after a low monomer conversion for the top and bottom surfaces. The extra-opaque shade of this composite may have facilitated low light transmission to the bottom, reducing the DC. 


\section{Conclusions}

The null hypothesis tested in this investigation was rejected. Opaque materials such as Natural Flow OA2 might properly be used to seal tooth fissures. The use of a high-intensity LED to photoactivate dental flowable materials at curing times lower than 60 seconds may facilitate their placement in vivo without compromising their physical properties.

\section{References}

1. Voltarelli FR, dos Santos-Daroz CB, Alves MC, Peris AR, Marchi GM. Effect of different light-curing devices and aging procedures on composite knoop microhardness. Braz Oral Res. 2009 Oct-Dec;23(4):473-9.

2. Rastelli AN, Jacomassi DP, Bagnato VS. Effect of power densities and irradiation times on the degree of conversion and temperature increase of a microhybrid dental composite resin. Laser Phys. 2008 Sep;18(9):1074-9.

3. Borges BC, Souza-Júnior EJ, Catelan A, Lovadino JR, dos Santos PH, Paulillo LA, Aguiar FH. Influence of the extended light exposure time on the degree of conversion and plasticization of materials used as pit and fissure sealants. J Investig Clin Dent. 2010 Nov;1(2):151-5.

4. Costa SX, Martins LM, Franscisconi PA, Bagnato VS, Saad JR, Rastelli AN, et al. Effect of different light sources and photo-activation methods on degree of conversion and polymerization shrinkage of a nanocomposite resin. Laser Phys. 2009 Dec;19(12):2210-18.

5. Calheiros FC, Daronch M, Rueggeberg FA, Braga RR. Influence of irradiant energy on degree of conversion, polymerization rate and shrinkage stress in an experimental resin composite system. Dent Mater. 2008 Sep;24(9):1164-8.

6. Imazato S, McCabe JF, Tarumi H, Ehara A, Ebisu S. Degree of conversion of composites measured by DTA and FTIR. Dent Mater. 2001 Mar;17(2):178-83.

7. Takahashi Y, Imazato S, Russell RR, Noiri Y, Ebisu S. Influence of resin monomers on growth of oral streptococci. J Dent Res. 2004 Apr;83(4):302-6.

8. Yue C, Tantbirojn D, Grothe RL, Versluis A, Hodges JS, Feigal RJ. The depth of cure of clear versus opaque sealants

\section{Acknowledgements}

The authors thank Biodinâmica (Ibiporã, Brazil), DFL (Rio de Janeiro, Brazil), and FGM (Joinville, Brazil) for the courtesy of providing the flowable composites used in this study.

as influenced by curing regimens. J Am Dent Assoc. 2009 Mar;140(3):331-8.

9. Aguiar FH, Lazzari CR, Lima DA, Ambrosano GM, Lovadino JR. Effect of light curing tip distance and resin shade on microhardness of a hybrid resin composite. Braz Oral Res. 2005 Oct-Dec;19(4):302-6.

10. Rode KM, Kawano Y, Turbino ML. Evaluation of curing light distance on resin composite microhardness and polymerization. Oper Dent 2007 Dec;32(6):571-8.

11. Rueggeberg FA, Caughman WF, Curtis JW Jr, Davis HC. Factors affecting cure at depths within light-activated resin composites. Am J Dent. 1993 Apr;6(2):91-5.

12. Fujita K, Nishiyama N, Nemoto K, Okada T, Ikemi T. Effect of base monomer's refractive index on curing depth and polymerization conversion of photo-cured resin composites. Dent Mater J. 2005 Sep;24(3):403-8.

13. Shortall AC, Palin WM, Burtscher P. Refractive index mismatch and monomer reactivity influence composite curing depth. J Dent Res. 2008 Jan;87(1):84-8.

14. Brandt WC, Schneider LF, Frollini E, Correr-Sobrinho L, Sinhoreti MA. Effect of different photo-initiators and light curing units on degree of conversion of composites. Braz Oral Res. 2010 Jul-Sep;24(3):263-70.

15. Alvim HH, Alecio AC, Vasconcellos WA, Furlan M, de Oliveira JE, Saad JR. Analysis of camphorquinone in composite resins as a function of shade. Dent Mater. 2007 Oct;23(10):1245-9.

16. Neumann MG, Miranda Jr WG, Schmitt CC, Rueggeberg FA, Correa IC. Molar extinction coefficients and the photon absorption efficiency of dental photoinitiators and light curing units. J Dent. 2005 Jul;33(6):525-32. 